\title{
Vitamin D in obstructive sleep apnea syndrome follow up and treatment: A study of $\mathbf{4 8 2}$ cases
}

\author{
Ayşe Karaoğullarından ${ }^{1}$, Birgül Tuhanioğlu ${ }^{1}$, Sanem Okşan Erkan ${ }^{1}$, Zeynel Abidin Erkan ${ }^{2}$ \\ ${ }^{1}$ ENT Department, Adana City Training and Research Hospital Yüreğir, Adana, Turkey \\ ${ }^{2}$ ENT Department, Private Clinic, Adana, Turkey
}

Received: 2021-06-09.

Accepted: 2021-07-26

This work is licensed under a Creative Commons Attribution 4.0 International License

\section{J Clin Med Kaz 2021; 18(5):63-69}

Corresponding author:

Ayșe Karaoğullarından.

E-mail: draysekara01@gmail.com;

ORCID: 0000-0002-7120-4962

\section{Abstract}

Aim: The aim of the study was to determine the factors associated with Obstructive Sleep Apnea Syndrome (OSAS) severity and vitamin D deficiency by examining routine laboratory parameters in patients with OSAS without comorbidities. We also aimed to see whether the severity of OSAS increased with decreasing levels of vitamin D.

Material and methods: Patients who presented to Adana City Training and Research Hospital, Ear Nose Throat Clinic with the symptoms of snoring and sleep apnea and who underwent polysomnography (PSG) in the sleep laboratory of the Otorhinolaryngology Clinic were included in the study. Blood results were analyzed retrospectively from the hospital information system. The patients were divided into groups according to their Apnea hypopnea Index (AHI) values as simple snoring, mild OSAS, moderate OSAS, and severe OSAS. According to the vitamin D values, the patients were categorized as sufficient $>30 \mathrm{ng} / \mathrm{ml}$, insufficient $20-30 \mathrm{ng} / \mathrm{ml}$ and deficient $<20 \mathrm{ng} / \mathrm{ml}$.

Results: Out of the 777 patients examined 482 patients fulfilling the inclusion criteria were analyzed for the study. It was seen that severity of OSAS increased concomitantly with decreasing Vitamin D levels.

Conclusion: Vitamin D deficiency is observed in patients with OSAS and is related to the severity of the disease. We think that vitamin D therapy may be beneficial in reducing the severity of the disease.

Key words: obstructive sleep apnea syndrome, polysomnography, vitamin D, apnea hypopnae index, parathormone

\section{Introduction}

Obstructive sleep apnea syndrome (OSAS) is a disorder characterized by recurrent episodes of partial or complete obstruction in the upper airway during sleep and increased respiratory effort, oxygen desaturation, sleep interruption, and excessive daytime sleepiness. Clinically, snoring is the most prominent symptom in patients with OSAS. Apart from snoring, nighttime symptoms such as apnea, nocturia, night sweats, dry mouth, frequent awakening, and daytime symptoms such as headache, excessive daytime sleepiness, concentration disorder, cognitive and mood changes are observed. OSAS affects 3-9\% of middle-aged women and $10-17 \%$ of men [1]. Obesity, advanced age, menopause, anatomic disorders of the head and neck, male sex, smoking, alcohol, and sedative drugs play a role in the development of OSAS [2]. Psychiatric symptoms such as cognitive impairment, depression, irritability, and anxiety may appear as the referral symptoms of OSAS. To diagnose OSAS, which can cause serious health problems, there is no biochemical parameter other than a detailed anamnesis taken during clinical evaluation and physical examination is insufficient. Therefore, in addition to clinical evaluation, the presence of sleep-related breathing disorder should be demonstrated objectively for diagnosis.

Currently, the gold standard diagnostic test in the diagnosis of respiratory-related sleep disorders is polysomnography (PSG) performed in the sleep laboratory [3]. However, we know that in clinical practice, sleep disorders are diagnosed late due to various reasons such as the increase in patient density and insufficient training in primary care medicine, and therefore delays in treatment. Sympathetic activation, endothelial dysfunction, systemic inflammation, and hypercoagulability occur with hypoxiareoxygenation attacks in patients with OSAS. As a result, various endocrinopathies such as high blood pressure, high glucose, increased waist circumference, low highdensity lipoprotein (HDL), high triglyceride levels, and osteoporosis can be seen $[4,5]$. 
Vitamin D is a fat-soluble vitamin that plays a role in bone and mineral metabolism. Vitamin D is taken into our body orally with food or is created in the skin by sunlight [6]. Serum 25-hydroxy vitamin D levels are used to determine vitamin D levels in our body [7]. Vitamin D deficiency results in a decrease in intestinal calcium absorption, leading to a decrease in serum calcium concentration. Vitamin D plays a role in the regulation of bone metabolism and calcium homeostasis. In addition, vitamin D receptors play an important role in the regulation of changes in the sleep-wake cycle in many brain regions including the hypothalamus. Low Vitamin D levels in the blood cause weakness in the skeletal and muscular system [8]. In Vitamin D deficiency, musculoskeletal functions deteriorate and the incidence and severity of OSAS increase due to the decrease in muscle tone in the upper respiratory tract [9]. Low Vitamin D levels are associated with airway inflammations such as rhinitis, adenoiditis, tonsillar hypertrophy, and this increases the severity of OSAS [10,11].

Different results were obtained in studies examining the relationship between OSAS and vitamin D in the literature. The aim of the study was to determine the factors associated with Obstructive Sleep Apnea Syndrome (OSAS) severity and vitamin D deficiency by examining routine laboratory parameters in patients with OSAS without comorbidities. We also aimed to see whether the severity of OSAS increased with decreasing levels of vitamin $\mathrm{D}$.

\section{Material and methods}

Patients who presented to Adana City Training and Research Hospital, Ear Nose Throat Clinic with the symptoms of snoring and sleep apnea and who underwent PSG in the sleep laboratory of the Otorhinolaryngology Clinic between June 2019 and December 2019 were included in the study. Before PSG, blood is routinely taken from patients for a hemogram and biochemistry tests to determine the presence of any endocrinologic disorders. Inclusion criteria are; patients without diabetes mellitus (DM), coronary artery disease (KAH), hypertension (HT), metabolic syndrome (MS), cancer, autoimmune diseases, musculoskeletal disease, cerebrovascular diseases (SVO). Patients whose blood results were registered in the hospital information system were included in the study. Patients who had any disease that could affect vitamin D and PTH levels or who used vitamin D externally were excluded from the study.

Before the PSG test, blood samples were taken from all patients (12 hours fasting) for the measurement of vitamin D serum levels and other biochemical parameters. After coagulation, the tubes were centrifuged and kept at $-80^{\circ} \mathrm{C}$ until required for analysis. Serum vitamin D was measured by ARCHITECT $25(\mathrm{OH}) \mathrm{D}$ chemiluminescent microparticle immunoassay (Abbott Diagnostics, Wiesbaden, Germany) [12]. This method is an automated calibration instrument system consisting of an immunoassay for the quantitative measurement of $25(\mathrm{OH}) \mathrm{D}$. PSG and blood results were analyzed retrospectively. The study was approved by Adana City Training and Research Hospital Clinical Research Ethics Committee (Date: July 1st, 2020; Decision: 963).

PSGrecordings ofall patients were evaluated retrospectively and cross-sectionally. Sleep and physiologic variables were monitored using a Comet-PLUS Grass ${ }^{\circledR}$ (Astro-Med Industrial Park, West Warwick, USA) PSG. Electroencephalography (EEG) with 10 channels (C3, C4, O1, O2, Fp1, Fp2, F3, F4, P3, P4), submental electromyography (EMG), right and left eye electrooculography (EOG), electrocardiography (ECG), oronasal airflow (thermal sensor and nasal pressure transducer), body position, thoracic and abdominal motion meter (inductance plethysmograph), arterial blood oxygen saturation measurement with finger pulse oximetry, left and right leg motion sensors (EMG), and a tracheal microphone were used.

Apnea was defined as a reduction of more than $90 \%$ in the airflow signal measured by the thermal sensor for at least 10 seconds. Hypopnea was defined as a decrease in nasal pressure signal for at least 10 seconds, more than 30\% compared with basal, and resulting in desaturation or arousal more than $3 \%$ compared with basal. The AHI value is obtained by dividing the sum of the apnea and hypopnea numbers by the person's sleep time. Thus, the AHI in 1 hour is revealed Apnea-Hypopnae Index (AHI) 0-4.9 = simple snoring, AHI 5-14.9= mild OSAS; and AHI: 15-29.9 were evaluated as moderate OSAS, and AHI $>30$ as severe OSAS. The patients were divided into groups according to their AHI values as simple snoring, mild OSAS, moderate OSAS, and severe OSAS. BMI was calculated by measuring height and weight by the same person using sensitive scales and a tape measure in the outpatient clinic.

Blood results were analyzed retrospectively from the hospital information system. The patients' Vitamin D, parathormone $(\mathrm{PTH})$, total cholesterol, triglyceride, low-density lipoprotein (LDL), high-density lipoprotein (HDL), ferritin, thyroid-stimulating hormone (TSH), B 12, and hemoglobin (HGB) values were recorded by the same person. According to the vitamin $\mathrm{D}$ values, the patients; Cathogarized as sufficient $>30 \mathrm{ng} / \mathrm{ml}$, insufficient $20-30 \mathrm{ng} / \mathrm{ml}$ and deficient $<20 \mathrm{ng} / \mathrm{ml}$.

The analysis of the data was performed using the SPSS 22.0 package program. Demographic information and clinical characteristics of patients p1: Kruskal Wallis test, p2: Chisquare test (percentages are evaluated according to rows) * It was made with the Linear-by-Linear Association and meanmedian values were given. The hemogram and biochemistry values of the patients were compared with the Kruskal Walls test according to the groups and the median-mean values were determined. Multiple Binary Logistic Regression between Mild + moderate + severe OSAS with simple OSAS was done. $\mathrm{P}<0.05$ was considered significant.

\section{Results}

Out of the 777 patients examined 482 patients fulfilling the inclusion criteria were analysed for the study. 87 patients were evaluated as simple snoring, 133 patients as mild OSAS, 102 patients as moderate OSAS, and 160 patients as severe OSAS (Table 1).

Medians of age differ according to AHI groups ( $\mathrm{p}=0.002)$. Accordingly, this difference is between the simple snoring and severe OSAS groups $(\mathrm{p}<0.05)$. The average age of the severe OSAS group is the highest. BMI medians differ according to AHI groups $(p<0.001)$. Accordingly, this difference is between the simple snoring and moderate and severe OSAS, mild and severe OSAS, moderate and severe OSAS $(p<0.05)$. Severe OSAS group with the highest BMI. A significant relationship was found between AHI and gender $(p=0.021)$. Accordingly, the rate of males in the severe OSAS was higher than the simple snoring, mild and moderate group, and the rate of males in the moderate OSAS was higher compared to the simple snoring $(p<0.05)$. The group with the highest male gender is the severe OSAS group. A significant relationship was found between AHI and smoking ( $p=0.021$ ). Accordingly, the proportion of smokers in the sever OSAS was higher than that of the simple snoring, mild and moderate group, and the proportion of smokers in the moderate OSAS group was higher than that of the simple snoring $(\mathrm{p}<0.05)$. The highest smoking rate is in the severe OSAS group. 


\begin{tabular}{|c|c|c|c|c|c|c|c|c|c|c|c|}
\hline & \multicolumn{2}{|c|}{ Total $(n=482)$} & \multicolumn{2}{|c|}{ Simple snoring $(\mathrm{n}=87)$} & \multicolumn{2}{|c|}{ Mild OSAS (n=133) } & \multicolumn{2}{|c|}{ Moderate OSAS $(n=102)$} & \multicolumn{2}{|c|}{ Severe OSAS $(n=160)$} & $\mathrm{p} 1$ \\
\hline & \multicolumn{2}{|c|}{$\begin{array}{l}\text { Median [IQR] } \\
\text { Mean(SD) }\end{array}$} & \multicolumn{2}{|c|}{$\begin{array}{l}\text { Median [IQR] } \\
\text { Mean(SD) }\end{array}$} & \multicolumn{2}{|c|}{$\begin{array}{l}\text { Median [IQR] } \\
\text { Mean(SD) }\end{array}$} & \multicolumn{2}{|c|}{$\begin{array}{l}\text { Median [IQR] } \\
\text { Mean(SD) }\end{array}$} & \multicolumn{2}{|c|}{$\begin{array}{l}\text { Median [IQR] } \\
\text { Mean(SD) }\end{array}$} & \\
\hline Age & \multicolumn{2}{|c|}{$\begin{array}{l}45.13 \pm 11.07 \\
45[37.5-53]\end{array}$} & \multicolumn{2}{|c|}{$\begin{array}{l}41.38 \pm 11.54 \\
43[33-49]\end{array}$} & \multicolumn{2}{|c|}{$\begin{array}{l}45.07 \pm 10.43 \\
45[37-52]\end{array}$} & \multicolumn{2}{|c|}{$\begin{array}{l}44.58 \pm 11.14 \\
46[38.75-51.25]\end{array}$} & \multicolumn{2}{|c|}{$\begin{array}{l}47.58 \pm 10.74 \\
47[40-55]\end{array}$} & 0.002 \\
\hline BMI & \multicolumn{2}{|c|}{$\begin{array}{l}29.9 \pm 6.03 \\
29[27-32]\end{array}$} & \multicolumn{2}{|c|}{$\begin{array}{l}28.46 \pm 7.51 \\
28[25-29]\end{array}$} & \multicolumn{2}{|c|}{$\begin{array}{l}28.73 \pm 4.28 \\
28[26-30]\end{array}$} & \multicolumn{2}{|c|}{$\begin{array}{l}29.56 \pm 4.82 \\
29[27-31]\end{array}$} & \multicolumn{2}{|c|}{$\begin{array}{l}31.88 \pm 6.59 \\
31[29-35]\end{array}$} & $<0.001$ \\
\hline & $\mathrm{N}$ & $\%$ & $\mathrm{n}$ & $\%$ & $\mathrm{~N}$ & $\%$ & $\mathrm{n}$ & $\%$ & $\mathrm{n}$ & $\%$ & p2 \\
\hline \multicolumn{12}{|l|}{ Sex } \\
\hline Male & 358 & 74.3 & 50 & 58.6 & 90 & 68.4 & 76 & 74.5 & 139 & 87.5 & \multirow[t]{2}{*}{$<0.001$} \\
\hline Female & 124 & 25.7 & 36 & 41.4 & 42 & 31.6 & 26 & 25.5 & 20 & 12.5 & \\
\hline \multicolumn{12}{|l|}{ Smoking } \\
\hline No & 291 & 60.4 & 67 & 77.0 & 90 & 68.4 & 60 & 58.8 & 73 & 45.6 & \multirow[t]{2}{*}{$<0.001$} \\
\hline Yes & 191 & 39.6 & 20 & 23.0 & 42 & 31.6 & 42 & 41.2 & 87 & 54.4 & \\
\hline \multicolumn{12}{|l|}{ Vitamin D } \\
\hline Deficiency & 336 & 69.7 & 54 & 62.1 & 94 & 70.7 & 70 & 68.6 & 118 & 73.8 & \multirow[t]{4}{*}{$0.021^{*}$} \\
\hline İnsufficiency & 111 & 23.0 & 24 & 27.6 & 27 & 20.3 & 21 & 20.6 & 39 & 24.4 & \\
\hline \multicolumn{11}{|l|}{ Sufficiency } & \\
\hline & 35 & 7.3 & 9 & 10.3 & 12 & 9.0 & 11 & 10.8 & 3 & 1.8 & \\
\hline
\end{tabular}

p1: Kruskal Wallis test, p2: Chi-square test (percentages are evaluated according to rows) * Linear-by-Linear Association BMI:Body mass index

A significant relationship was found between AHI and vitamin D levels ( $\mathrm{p}=0.021$ ). Accordingly, the ratio of simple snoring, mild and moderate OSAS was higher in the sufficiency group than the heavy OSAS $(\mathrm{p}<0.05)$. Vitamin D is deficient in $73.8 \%$ of the severe OSAS group, $68.6 \%$ of the moderate OSAS group, and $62 \%$ of the mild OSAS group. The group with the highest vitamin D deficiency is the severe OSAS group (Table 1).

Total Cholesterol medians differ according to AHI groups $(p=0.003)$. Accordingly, this difference is between the simple snoring and moderate and severe, mild and severe OSAS ( $p$ $<0.05$ ). The highest cholesterol levels were seen in severe OSAS . Triglyceride medians differ according to AHI groups $(\mathrm{p}<0.001)$. Accordingly, this difference is between the simple snoring and mild, mild and severe, moderate and severe OSAS $(p<0.05)$. The highest Triglyceride levels were seen in severe OSAS. HDL medians differ according to AHI groups $(\mathrm{p}=0.009)$. Accordingly, this difference is between severe and mild and moderate OSAS $(\mathrm{p}<0.05)$. The highest HDL levels were seen in mild OSAS. HGB medians differ according to AHI groups $(p=0.009)$. Accordingly, this difference is between the simple snoring and severe OSAS $(\mathrm{p}<0.05)$. The highest hemoglobin levels were seen in severe OSAS. The group with the lowest vitamin D level is the severe OSAS group (Table 2).

Table 2 Hemogram and biochemistry values of study subjects according to the severity of OSAS

\begin{tabular}{|c|c|c|c|c|c|c|c|c|c|c|c|}
\hline & \multicolumn{2}{|l|}{$\begin{array}{l}\text { Total } \\
(\mathrm{n}=482)\end{array}$} & \multicolumn{2}{|c|}{ Simple snoring $(\mathrm{n}=87)$} & \multicolumn{2}{|c|}{ Mild OSAS (n=133) } & \multicolumn{2}{|c|}{ Moderate OSAS $(n=102)$} & \multicolumn{2}{|c|}{ Severe OSAS $(n=160)$} & \multirow[b]{2}{*}{$\mathrm{P}$} \\
\hline & Mean(SD) & Median [IQR] & Mean(SD) & Median [IQR] & Mean(SD) & Median [IQR] & Mean(SD) & Median [IQR] & Mean(SD) & Median [IQR] & \\
\hline Parathormone & $\begin{array}{l}49.58 \\
\pm 26.21 \\
\end{array}$ & $47[33-60]$ & $\begin{array}{l}52.71 \pm \\
41.91 \\
\end{array}$ & $47[34-60]$ & \begin{tabular}{|l|}
$48.84 \pm$ \\
21.15 \\
\end{tabular} & 47 [33.25-63] & \begin{tabular}{|l|}
$47.6 \pm$ \\
23.65 \\
\end{tabular} & 45 [28-61.5] & \begin{tabular}{|l|}
$49.74 \pm$ \\
19.79 \\
\end{tabular} & $\begin{array}{l}47 \text { [35.25- } \\
60] \\
\end{array}$ & 0.646 \\
\hline Total Cholesterol & \begin{tabular}{|l|}
223.21 \\
\pm 176.98 \\
\end{tabular} & 200 [154-254] & \begin{tabular}{|l|}
$200.39 \pm$ \\
121.27 \\
\end{tabular} & \begin{tabular}{|l}
$187[123-$ \\
$221]$
\end{tabular} & $\begin{array}{l}201.09 \pm \\
86.97\end{array}$ & 200 [131-250] & \begin{tabular}{|l|}
$218.27 \pm$ \\
96.45 \\
\end{tabular} & $\begin{array}{l}200.5 \text { [157.25- } \\
242.25]\end{array}$ & \begin{tabular}{|l|}
$257.17 \pm$ \\
270.24 \\
\end{tabular} & $\begin{array}{l}210 \text { [170- } \\
268]\end{array}$ & 0.003 \\
\hline Triglyceride & \begin{tabular}{|l|}
228.44 \\
\pm 151.99
\end{tabular} & $\begin{array}{l}193 \text { [129.75- } \\
276.25]\end{array}$ & $\begin{array}{l}188.13 \pm \\
150.35\end{array}$ & $\begin{array}{l}145 \text { [99.5- } \\
228.5]\end{array}$ & $\begin{array}{l}211.75 \pm \\
131.65\end{array}$ & $\begin{array}{l}183[115.5- \\
274.5]\end{array}$ & \begin{tabular}{|l|}
$226.26 \pm$ \\
126.93
\end{tabular} & $\begin{array}{l}201 \text { [149.75- } \\
266.75]\end{array}$ & \begin{tabular}{|l|}
$265.16 \pm$ \\
174.76
\end{tabular} & \begin{tabular}{|l|}
215.5 \\
{$[158.25-$} \\
$308.25]$ \\
\end{tabular} & $<0.001$ \\
\hline LDL & $\begin{array}{l}139.44 \\
\pm 41.05 \\
\end{array}$ & $\begin{array}{l}141 \text { [115- } \\
161.5]\end{array}$ & $\begin{array}{l}132.88 \pm \\
44.79 \\
\end{array}$ & \begin{tabular}{|l}
$121[100-$ \\
$154.5]$ \\
\end{tabular} & $\begin{array}{l}141.06 \pm \\
46.82\end{array}$ & $\begin{array}{l}148[111.25- \\
169.75]\end{array}$ & $\begin{array}{l}140.03 \pm \\
38.4 \\
\end{array}$ & $\begin{array}{l}143[116.75- \\
163]\end{array}$ & $\begin{array}{l}141.28 \pm \\
35.24\end{array}$ & $\begin{array}{l}141 \text { [123- } \\
160]\end{array}$ & 0.036 \\
\hline HDL & $\begin{array}{l}47.94 \pm \\
23.82\end{array}$ & $43[37-50]$ & $\begin{array}{l}45.47 \pm \\
15.45\end{array}$ & $43[37-50.5]$ & $\begin{array}{l}51.19 \pm \\
27.09\end{array}$ & 45 [38.5-52] & \begin{tabular}{|l}
$50.03 \pm$ \\
25.74 \\
\end{tabular} & $\begin{array}{l}44.5[37.75- \\
50]\end{array}$ & $\begin{array}{l}45.26 \pm \\
23.15\end{array}$ & $40[36-48]$ & 0.009 \\
\hline Ferritin & \begin{tabular}{|l|}
$70.83 \pm$ \\
66.2 \\
\end{tabular} & 50 [23-93] & \begin{tabular}{|l}
$63.17 \pm$ \\
65.12 \\
\end{tabular} & $44[20-86]$ & $\begin{array}{l}64.55 \pm \\
58.89 \\
\end{array}$ & $45[25-85]$ & \begin{tabular}{|l|}
$70.43 \pm$ \\
64.93 \\
\end{tabular} & 55.5 [21-91] & $\begin{array}{l}80.52 \pm \\
72.44 \\
\end{array}$ & $\begin{array}{l}56[29.5- \\
110] \\
\end{array}$ & 0.073 \\
\hline TSH & \begin{tabular}{|l|}
$1.74 \pm$ \\
3.07 \\
\end{tabular} & $1[0.9-2]$ & $\begin{array}{l}.45 \pm \\
1.06\end{array}$ & $1[1-2]$ & $1.47 \pm 1.11$ & $1[0.9-1.9]$ & $\begin{array}{l}1.74 \pm \\
2.37 \\
\end{array}$ & 1 [0.9-1.95] & $\begin{array}{l}2.13 \pm \\
4.82 \\
\end{array}$ & $1[1-2]$ & 0.618 \\
\hline B12 vitamin & \begin{tabular}{|l|}
$220.92 \pm$ \\
127.02 \\
\end{tabular} & $\begin{array}{l}197 \text { [144.25- } \\
257]\end{array}$ & $\begin{array}{l}253.52 \pm \\
176.25 \\
\end{array}$ & $\begin{array}{l}203 \text { [158.5- } \\
278]\end{array}$ & $\begin{array}{l}213.59 \pm \\
84.14\end{array}$ & $\begin{array}{l}200[149.5- \\
260]\end{array}$ & \begin{tabular}{|l|}
$216.91 \pm$ \\
135.91 \\
\end{tabular} & $\begin{array}{l}192.5 \text { [141.75- } \\
250.25]\end{array}$ & \begin{tabular}{|l|}
$211.99 \pm$ \\
117.31 \\
\end{tabular} & \begin{tabular}{|l|}
$192[137-$ \\
$250]$
\end{tabular} & 0.266 \\
\hline HGB & $13.9 \pm 2.14$ & 14 [13-15] & $\begin{array}{l}13.43 \pm \\
2.12\end{array}$ & 14 [13-15] & $\begin{array}{l}13.98 \pm \\
2.94\end{array}$ & 14 [13-15] & $\begin{array}{l}13.75 \pm \\
1.53 \\
\end{array}$ & 14 [13-15] & \begin{tabular}{|l|}
$14.18 \pm$ \\
1.58 \\
\end{tabular} & $15[13-15]$ & 0.006 \\
\hline D vitamin & $18.23 \pm 9.5$ & $17[12-22]$ & $\begin{array}{l}19.59 \pm \\
10.77\end{array}$ & $18[12-25]$ & $\begin{array}{l}18.67 \pm \\
8.95\end{array}$ & 18 [12.5-22] & \begin{tabular}{|l|}
$18.74 \pm$ \\
10.61
\end{tabular} & 15 [12-22] & $\begin{array}{l}16.79 \pm \\
8.29\end{array}$ & $15.5[11-21]$ & 0.158 \\
\hline
\end{tabular}

p: Kruskal Wallis test

LDL:Low-density lipoprotein cholesterol , HDL: high- density lipoprotein cholesterol TSH: Thyroid Stimulating Hormone HGB:Hemoglobine 


\begin{tabular}{|c|c|c|c|c|}
\hline \multirow[t]{3}{*}{ Table 3} & \multicolumn{4}{|c|}{$\begin{array}{l}\text { Multiple Binary Logistic Regression between } \\
\text { Mild+moderate+severe OSAS with simple OSAS }\end{array}$} \\
\hline & \multirow[t]{2}{*}{ Odds Ratio } & \multicolumn{2}{|c|}{ 95\% C.I.for Odds Ratio } & \multirow[t]{2}{*}{$\mathrm{p}$} \\
\hline & & Lower & Upper & \\
\hline Age & 1,037 & 1,014 & 1,060 & 0,001 \\
\hline Sex (female) & 0,368 & 0,221 & 0,612 & $<0,001$ \\
\hline Bmı & 1,055 & 1,001 & 1,111 & 0,045 \\
\hline $\begin{array}{l}\text { Vitamin d } \\
\text { (deficient) }\end{array}$ & Ref. & & & 0,123 \\
\hline $\begin{array}{l}\text { Vitamin d } \\
\text { (insufficient) }\end{array}$ & 0,604 & 0,345 & 1,056 & 0,077 \\
\hline $\begin{array}{l}\text { Vitamin d } \\
\text { (sufficient) }\end{array}$ & 0,554 & 0,236 & 1,303 & 0,176 \\
\hline Constant & 0,315 & & & 0,167 \\
\hline
\end{tabular}

p:Multiple Binary Logistic Regression

Figure 1 - Correlation of serum vitamin D level with apneahypopnea index (AHI) in all subjects

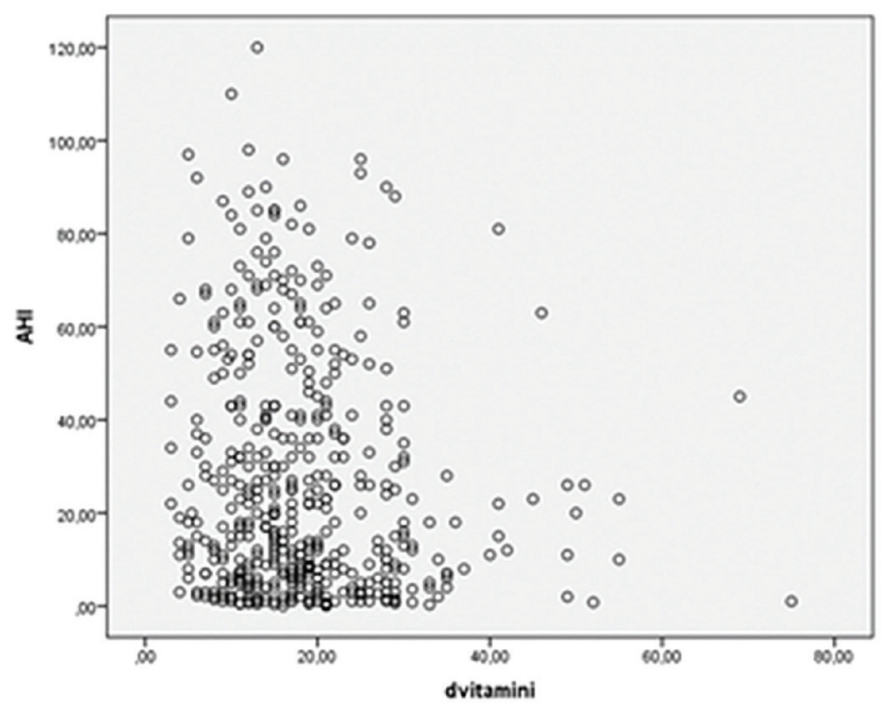

Age in mild + moderate+severe OSAS patients compared to simple OSAS patients 1.037, female 0.368 and BMI 1.055 times $(p<0.05)$. Vitamin D level was not significant $(p>0.05)$ (Table 3$)$.

There is a very weak negative correlation between $\mathrm{AHI}$ and vitamin $\mathrm{D}(\mathrm{r}=-0.112 ; \mathrm{p}=0.014)$. Generally, as AHI increased, vitamin D level decreased (Figure 1). The mean AHI of the group with Vitamin D deficiency was 29.9, the mean AHI of the group with Vitamin D insufficient was 24.7, and the mean of the group with Vitamin D sufficient was 16.04.

\section{Discussion}

OSAS is an inflammatory disease with hypoxia and reoxygenation attacks. There are many studies in the literature investigating the relationship between OSAS and Vitamin D [12]. Vitamin D has an important role in the control of bone and mineral metabolism, and it is also effective in regulating the sleep-wake cycle because it has receptors at many points in the brain, especially in the hypothalamus. Since our study was performed on patients who came to the outpatient clinic with the suspicion of OSAS, Vitamin D deficiency was observed with a high rate of $69.7 \%$. Vitamin D level decreased as the severity of OSAS increased. In addition, total cholesterol, Triglyceride, LDL and hemoglobin levels were higher in the severe OSAS group. No significant relationship was found in parathyroid hormone levels. Severe OSAS group had higher mean age, higher BMI and smoking rates.
Kul et al. found that vitamin D levels were significantly lower in patients with OSAS compared with the control group, but BMI and PTH levels were higher. The lowest vitamin D level and highest PTH level were found in the severe OSAS group. Therefore, eliminating vitamin D deficiency in these patients may reduce the severity of the disease and contribute to the treatment process [13]. As in our study, patients with OSAS had vitamin D deficiency and this rate was higher in patients with severe OSAS.

Vitamin D is a steroid hormone that plays an important role in Ca-P (phosphorus) metabolism and bone mineralization. Ethnic origin, physical activity, nutrition, smoking, obesity, and genetic reasons affect vitamin D metabolism. Çelikhisar et al. used the Berlin Sleepiness Questionnaire on city bus drivers and according to the survey, performed PSG on individuals at high risk for OSAS. According to the AHI values, patients with mild OSAS were included in the control group, and those with moderate-severe OSAS were included in the patient group. No statistically significant difference was found between the control group and the patient group regarding age, phosphorus, calcium, serum Vitamin D, and serum PTH levels. In some OSAS diseases, vitamin D levels are not low. In our study, age was higher and smoking was found to be higher with BMI in the severe OSAS group. The lowest Vitamin D level was found in the severe OSAS group. However, Çelikhiisar et al. As it is, there was no significant difference in PTH levels. Variables such as occupation, age, physical activity, gender, weight can produce different results in the relationship between OSAS and vitamin $\mathrm{D}$. It is known that acceleration, brake movements and stop-and-go movements are quite frequent in urban traffic due to heavy traffic and traffic lights. Therefore, hip, leg, and arm activity is quite high. This type of physical activity is equivalent to regular exercise, which can cause normal vitamin $\mathrm{D}$ values and not detecting high PTH levels, such as in those who exercise regularly [3].

Vitamin D and PTH, except for bone and Ca metabolism is also associated with obesity, DM, MS, and insulin resistance (IR) [14]. Vitamin D treatment decreases systemic inflammation by decreasing insulin resistance [15]. Vitamin D deficiency and PTH elevations in patients with OSAS are associated with abnormal glucose metabolism. Zegin Fan et al. found that IR in the severe OSAS group was significantly higher than in the control group. Vitamin D values are negatively correlated with AHI and IR [16]. We did not measure IR, because the study was retrospective and this was not our aim. But we eliminated those with comorbid disease detectable by background reports at the beginning of the study.

OSAS is a disease that progresses with complete or partial obstruction of the upper respiratory tract and causes hypoxia and sleep interruption. Continuous positive airway pressure (CPAP) therapy is the best treatment method today. Claudio et al. found that after seven nights of CPAP treatment, vitamin D levels of male patients who responded to treatment were significantly higher than before the CPAP treatment. They could not find the same increase in female patients who responded to the treatment. This study concluded that short-term CPAP therapy increased vitamin D levels in male patients. OSAS often affects women after menopause. The same effect may not be seen in women because postmenopausal hormones are important in vitamin D regulation. In the future, more studies are needed to investigate the positive effects of CPAP treatment on vitamin D and PTH levels [17]. 
Salepci et al. concluded that there was no difference between the vitamin D levels of patients with and without OSAS. They also found no relationship between vitamin D levels and diabetes, age, ODI, and min SO2 [18]. This may be because the study groups were small, it was a cross-sectional study, and many factors affect vitamin D levels. Some studies of populations in developing countries, including Turkey, reported having low levels of vitamin D [19]. Forty-seven percent of the population in a population-based study conducted in Turkey had vitamin $\mathrm{D}$ deficiency with an average vitamin $\mathrm{D}$ level of $22.8 \mathrm{ng} / \mathrm{mL}$ [20]. In our study, vitamin D levels are lower than the general population in Turkey because we measured the level of vitamin D in patients undergoing PSG.

Barcela et al. divided patients with OSAS into three groups according to their vitamin D levels as normal, low and very low. Patients with very low vitamin D levels have higher AHI, arousal index, glucose, cholesterol, triglyceride, and PTH levels, and minSO2, and mean $\mathrm{SO} 2$ values are lower in older patients [21]. In our study, we grouped the patients according to AHI level, not Vitamin D level. We found the highest total cholesterol, triglyceride, and LDL values in the severe OSAS group, the group with the lowest vitamin D levels in the severe OSAS group.

There are different hypotheses to explain the relationship between OSAS and vitamin D. Pro-inflammatory cytokines increase in vitamin D deficiency, and anti-inflammatory cytokines decrease. Thus, with the increase of inflammatory pathways, vitamin D deficiency may cause OSAS [22]. Also, as in chronic obstructive pulmonary disease (COPD), hypoxia may be the cause of vitamin D deficiency in patients with OSAS [23]. Another important issue is inadequate vitamin D levels; adenotonsillar hypertrophy may increase the risk of OSAS by causing chronic rhinitis and upper respiratory muscle myopathy [24]. Limited exposure to sunlight due to excessive daytime sleepiness, restricted physical activity due to obesity, and inadequate nutrition are causes of vitamin D deficiency [25]. The ages, sexes and BMIs of the patient and control groups were matched in the study by Ahmed Abbas et al. The Epworth Sleepiness Scale (ESS) was applied to both groups, but PSG was not used with the control group. When the patients with OSAS were compared with the control group, ESS was higher and vitamin D values were lower. Vitamin D values are low in patients with OSAS and this correlates with the severity of the disease [26]. In the future, multi-center cross-sectional, prospective studies are needed to examine the effects of vitamin $\mathrm{D}$ treatment on disease severity and quality of life in patients with OSAS.

Some studies have shown that there are vitamin D receptors (VDR) in neuronal and glial tissues in the central nervous system, as in all tissues in the body [27]. VDRs are present in many regions of the human brain such as the prefrontal cortex, cingulate gyrus, thalamus, substantia nigra, and hippocampus, including the hypothalamus, a brain region that regulates the sleep-wake cycle [28]. Obstructive sleep apnea and short sleep duration are associated with low serum vitamin D levels. The greater proportion of sleep symptoms and disturbances in older adults may support that an age-related mechanism related to vitamin D affects serum levels and metabolism. Vitamin D deficiency is increasingly common in both OSA and sleep shortening, and is thought to be linked to the most common chronic diseases. In the study of Ronaldo et al. short sleep duration was evaluated as total sleep time $<6$ hours and Vitamin $\mathrm{D}$ deficiency $<30 \mathrm{ng} / \mathrm{mL}$. In their study, they concluded that age, sex, ethnicity, obesity, smoking, hypertension, diabetes, sedentary lifestyle, seasonality, and creatinine serum levels were associated with vitamin D deficiency in both OSAS and short sleep. To our knowledge, their study is the first to show that moderate to severe OSAS and short sleep duration are associated with vitamin D deficiency [29].

Vitamin D is one of the most important factors in hypoxia, reoxygenation attacks and cytokine release mechanism in OSAS [30]. It has been shown in many studies, that systemic biomarkers such as interleukin (IL)-6, C-reactive protein (CRP) and IL-17 increase in OSAS [31,32]. Redline et al. also found that IL-17 increased in OSAS and was related to the severity of OSAS [33]. To better understand the mechanisms of serum vitamin D deficiency and its relationship with inflammation in patients with OSAS, future multicenter clinical studies are needed.

OSAS is generally seen in a population with common obesity and is associated with endocrine pathologies such as T2DM [34-36]. Danyan et al. reported that serum vitamin D levels had no significant relationship with AHI; however, they stated that it increased the risk of OSAS in patients with T2DM [37]. The fact that most patients with T2DM patients were obese, the study being cross-sectional, and having a limited number of patients may have been the limitations of this study.

In a meta-analysis performed by Sikarin et al., it was stated that moderate and severe OSAS were associated with low vitamin D levels [38]. The low vitamin D level in OSAS is due to hypoxia caused by chronic obstructive pulmonary disease (COPD). This was the first systemic review and meta-analysis to investigate the relationship between OSAS and low vitamin D levels. There were no chronic diseases such as COPD in our patient population.

The limitations of our study include the effects of many diseases on vitamin D levels, the possibility of vitamin D supplementation even if there is no such record in the hospital data, and the fact that vitamin $\mathrm{D}$ levels can be affected by seasonal conditions and nutritional status.

\section{Conclusions}

Vitamin D deficiency is observed in patients with OSAS and is related to the severity of the disease. In the follow-up of patients with OSAS and compliance with treatment, instead of an expensive and time-consuming procedure like PSG, we can look at vitamin D levels in the outpatient clinic. We think that vitamin $\mathrm{D}$ therapy may be beneficial in reducing the severity of the disease.

Disclosures: There is no conflict of interest for all authors.

Acknowledgements: Asena Ayça Özdemir for statistical analysis from Mersin University/Turkey.

Funding: None. 


\section{References}

1. Archontogeorgis K, Nena E, Papanas N, Steiropoulos P. The role of vitamin D in obstructive sleep apnoea syndrome. Breathe (Sheff). 2018; 14(3):206-215. doi: 10.1183/20734735.000618. PMID: 30186518; PMCID: PMC6118887.

2. Archontogeorgis K, Papanas N, Rizos EC, Nena E, Zissimopoulos A, Tsigalou C, et all. Reduced Serum Vitamin D Levels Are Associated with Insulin Resistance in Patients with Obstructive Sleep Apnea Syndrome. Medicina (Kaunas). 2019; 55(5):174. doi: 10.3390/medicina55050174. PMID: 31137600; PMCID: PMC6572623.

3. Çelikhisar H., İlkhan G., Body Mass Index, 25- Hydroxy Vitamin D and Parathormone levels in City Bus Drivers with Obstructive Sleep Apnea Syndrome. Bozak Med J. 2020; 10(2):10-12. https://doi.org/10.16919/bozoktip.532840

4. Zicari AM, Occasi F, Di Mauro F, Lollobrigida V, Di Fraia M, Savastano V, et all. Mean Platelet Volume, Vitamin D and C Reactive Protein Levels in Normal Weight Children with Primary Snoring and Obstructive Sleep Apnea Syndrome. PLoS One. 2016; 11(4):e0152497. doi: 10.1371/journal.pone.0152497. PMID: 27054959; PMCID: PMC4824489.

5. Cassol CM, Martinez D, da Silva FABS, Fischer MK, Lenz MDCS, Bós ÂJG. Is sleep apnea a winter disease?: meteorologic and sleep laboratory evidence collected over 1 decade. Chest. 2012; 142(6):1499-1507. doi: 10.1378/chest.11-0493. PMID: 22700779.

6. Öncel G., Hüseyinoğlu N., Özlece H., Analysis of vitamin D Receptor Polymorphisms in Turkish Patients with Obstructive Sleep Apnea Syndrome. Dicle Med J. 2019; 46(4):771-78. https://doi.org/10.5798/dicletip.661358

7. Kheirandish-Gozal L, Peris E, Gozal D. Vitamin D levels and obstructive sleep apnoea in children. Sleep Med. 2014; 15(4):459-63. doi: 10.1016/j.sleep.2013.12.009. Epub 2014 Feb 7. PMID: 24684979; PMCID: PMC4247539.

8. Bischoff-Ferrari HA, Dietrich T, Orav EJ, Hu FB, Zhang Y, Karlson EW, et all. Higher 25-hydroxyvitamin D concentrations are associated with better lower-extremity function in both active and inactive persons aged $>$ or $=60 \mathrm{y}$. Am J Clin Nutr. 2004; 80(3):752-8. doi: 10.1093/ajen/80.3.752. PMID: 15321818.

9. Goswami U, Ensrud KE, Paudel ML, Redline S, Schernhammer ES, Shikany JM, et all. Osteoporotic Fractures in Men Study Research Group. Vitamin D Concentrations and Obstructive Sleep Apnea in a Multicenter Cohort of Older Males. Ann Am Thorac Soc. 2016; 13(5):712-8. doi: 10.1513/AnnalsATS.201507-440OC. PMID: 26845389; PMCID: PMC5018890.

10. Wang LF, Lee CH, Chien CY, Chen JY, Chiang FY, Tai CF. Serum 25-hydroxyvitamin D levels are lower in chronic rhinosinusitis with nasal polyposis and are correlated with disease severity in Taiwanese patients. Am J Rhinol Allergy. 2013; 27(6):e162-5. doi: 10.2500/ ajra.2013.27.3948. PMID: 24274207.

11. Johnson T, Avery G, Byham-Gray L. Vitamin D and metabolic syndrome. Topics Clin Nutr. 2009; 24:47-54. https://doi.org/10.1097/ TIN.0b013e31819897ad

12. Koivula MK, Matinlassi N, Laitinen P, Risteli J. Four automated 25-OH total vitamin D immunoassays and commercial liquid chromatography tandem-mass spectrometry in Finnish population. Clin Lab. 2013; 59(3-4):397-405. doi: 10.7754/clin.lab.2012.120527. PMID: 23724631.

13. Kul A., Araz Ö., The Relation between Obstructive Sleep Apnea Syndrome and Vitamin D, Van Medical Journal. 2020; $27(1): 50-55$. https://doi.org/10.5505/vtd.2020.98216

14. Karras SN, Anagnostis P, Antonopoulou V, Tsekmekidou X, Koufakis T, Goulis DG, et all. The combined effect of vitamin D and parathyroid hormone concentrations on glucose homeostasis in older patients with prediabetes: A cross-sectional study. Diab Vasc Dis Res. 2018; 15(2):150-153. doi: 10.1177/1479164117738443. Epub 2017 Nov 8. PMID: 29113459.

15. Mousa A, Naderpoor N, Teede H, Scragg R, de Courten B. Vitamin D supplementation for improvement of chronic low-grade inflammation in patients with type 2 diabetes: a systematic review and meta-analysis of randomized controlled trials. Nutr Rev. 2018; 76(5):380-394. doi: 10.1093/nutrit/nux077. PMID: 29490085.

16. Fan Z, Cao B, Long H, Feng L, Li Q, Zhang Y, et all. Independent association of vitamin D and insulin resistance in obstructive sleep apnea. Ann Endocrinol (Paris). 2019; 80(5-6):319-323. doi: 10.1016/j.ando.2019.09.004. Epub 2019 Nov 1. PMID: 31759518.

17. Liguori C, Romigi A, Izzi F, Mercuri NB, Cordella A, Tarquini E, et all. Continuous Positive Airway Pressure Treatment Increases Serum Vitamin D Levels in Male Patients with Obstructive Sleep Apnea. J Clin Sleep Med. 2015; 11(6):603-7. doi: 10.5664/jcsm.4766.

18. Salepci B, Caglayan B, Nahid P, Parmaksiz ET, Kiral N, Fidan A, et all. Vitamin D Deficiency in Patients Referred for Evaluation of Obstructive Sleep Apnea. J Clin Sleep Med. 2017; 13(4):607-612. doi: 10.5664/jcsm.6554. PMID: 27998376; PMCID: PMC5359338.

19. E. Öğüş, H. Sürer, A. Kılınç, Fidancı V., Yılmaz G., Dindar N., et all., Evaluation of Vitamin D Levels by Months, Sex and Age Ankara Med J. 2015; 15(1):1-5. doi:10.17098/amj.8887

20. Arabi A, El Rassi R, El-Hajj Fuleihan G. Hypovitaminosis D in developing countries-prevalence, risk factors and outcomes. Nat Rev Endocrinol. 2010; 6(10):550-61. doi: 10.1038/nrendo.2010.146. PMID: 20852586.

21. Barceló A, Esquinas C, Piérola J, De la Peña M, Sánchez-de-la-Torre M, Montserrat JM, et all. Vitamin D status and parathyroid hormone levels in patients with obstructive sleep apnea. Respiration. 2013; 86(4):295-301. doi: 10.1159/000342748. Epub 2012 Nov 15. PMID: 23154407.

22. Lin QC, Chen LD, Yu YH, Liu KX, Gao SY. Obstructive sleep apnea syndrome is associated with metabolic syndrome and inflammation. Eur Arch Otorhinolaryngol. 2014; 271(4):825-31. doi: 10.1007/s00405-013-2669-8. Epub 2013 Aug 31. PMID: 23995706.

23. Persson LJ, Aanerud M, Hiemstra PS, Hardie JA, Bakke PS, Eagan TM. Chronic obstructive pulmonary disease is associated with low levels of vitamin D. PLoS One. 2012; 7(6):e38934. doi: 10.1371/journal.pone.0038934. Epub 2012 Jun 21. PMID: 22737223; PMCID: PMC3380863.

24. McCarty DE, Chesson AL Jr, Jain SK, Marino AA. The link between vitamin D metabolism and sleep medicine. Sleep Med Rev. 2014; 18(4):311-9. doi: 10.1016/j.smrv.2013.07.001. Epub 2013 Sep 26. PMID: 24075129.

25. Johns MW. Reliability and factor analysis of the Epworth Sleepiness Scale. Sleep. 1992; 15(4):376-81. doi: 10.1093/sleep/15.4.376. PMID: 1519015.

26. Abbas A., Samah M. Serum vitamin D level is associated with obstructive sleep apnea state and severity The Egyptian Journal of Chest Diseases and Tuberculosis. 2020; 69:256-258 DOI:10.4103/ejcdt.ejcdt_207_18

27. Garcion E, Wion-Barbot N, Montero-Menei CN, Berger F, Wion D. New clues about vitamin D functions in the nervous system. Trends Endocrinol Metab. 2002; 13(3):100-5. doi: 10.1016/s1043-2760(01)00547-1. PMID: 11893522. 
28. Saper CB, Scammell TE, Lu J. Hypothalamic regulation of sleep and circadian rhythms. Nature. 2005; 437(7063):1257-63. doi: 10.1038/nature04284.

29. Piovezan RD, Hirotsu C, Feres MC, Cintra FD, Andersen ML, Tufik S, et all. Obstructive sleep apnea and objective short sleep duration are independently associated with the risk of serum vitamin D deficiency. PLoS One. 2017; 12(7):e0180901. doi: 10.1371/journal. pone.0180901. PMID: 28686746; PMCID: PMC5501615.

30. Barceló A, Esquinas C, Piérola J, De la Peña M, Sánchez-de-la-Torre M, Montserrat JM, et all. Vitamin D status and parathyroid hormone levels in patients with obstructive sleep apnea. Respiration. 2013; 86(4):295-301. doi: 10.1159/000342748. Epub 2012 Nov PMID: 23154407.

31. Toujani S, Kaabachi W, Mjid M, Hamzaoui K, Cherif J, Beji M. Vitamin D deficiency and interleukin-17 relationship in severe obstructive sleep apnea-hypopnea syndrome. Ann Thorac Med. 2017; 12(2):107-113. doi: 10.4103/atm.ATM_301_16. PMID: 28469721; PMCID: PMC5399684

32. Chambers ES, Hawrylowicz CM. The impact of vitamin D on regulatory T cells. Curr Allergy Asthma Rep. 2011; 11(1):29-36. doi: 10.1007/s11882-010-0161-8. PMID: 21104171.

33. Redline S, Tishler PV, Schluchter M, Aylor J, Clark K, Graham G. Risk factors for sleep-disordered breathing in children. Associations with obesity, race, and respiratory problems. Am J Respir Crit Care Med. 1999; 159(5 Pt 1):1527-32. doi: 10.1164/ajrccm.159.5.9809079. PMID: 10228121.

34. Einhorn D, Stewart DA, Erman MK, Gordon N, Philis-Tsimikas A, Casal E. Prevalence of sleep apnea in a population of adults with type 2 diabetes mellitus. Endocr Pract. 2007; 13(4):355-62. doi: 10.4158/EP.13.4.355. PMID: 17669711.

35. Nagayoshi M, Punjabi NM, Selvin E, Pankow JS, Shahar E, Iso H, et all. Obstructive sleep apnea and incident type 2 diabetes. Sleep Med. 2016; 25:156-161. doi: 10.1016/j.sleep.2016.05.009. Epub 2016 Sep 29. PMID: 27810258; PMCID: PMC5102826.

36. Aronsohn RS, Whitmore H, Van Cauter E, Tasali E. Impact of untreated obstructive sleep apnea on glucose control in type 2 diabetes. Am J Respir Crit Care Med. 2010; 181(5):507-13. doi: 10.1164/rccm.200909-1423OC. Epub 2009 Dec 17. PMID: 20019340; PMCID: PMC2830401.

37. Ma D, Zheng X, Dong L, Zheng C, Chen Y, Chen Z, et all. The Relationship of Serum 25-Hydroxyvitamin-D Level with Severity of Obstructive Sleep Apnea in Patients with Type 2 Diabetes Mellitus. Diabetes Metab Syndr Obes. 2020; 13:1391-1398. doi: 10.2147/ DMSO.S250694. PMID: 32440175; PMCID: PMC7211054.

38. Upala S, Sanguankeo A. Association between 25-Hydroxyvitamin D and Obstructive Sleep Apnea: A Systematic Review and MetaAnalysis. J Clin Sleep Med. 2015; 11(11):1347. doi: 10.5664/jcsm.5208. PMID: 26235155; PMCID: PMC4623137. 